\title{
Pueraria lobata Root Constituents as Xanthine Oxidase Inhibitors and Protective Agents against Oxidative Stress Induced in GES-1 Cells
}

\author{
Xiaosheng Tang, ${ }^{a}$ Aiping Xiao, ${ }^{b}$ Shiyong Mei, ${ }^{b}$ Ping Tang, ${ }^{*, c}$ Licheng Ren ${ }^{*, d}$ and \\ Liangliang Liu ${ }^{\oplus *, b}$
}

${ }^{a}$ Hubei Key Laboratory of Edible Wild Plants Conservation and Utilization, National Demonstration Center for Experimental Biology Education, College of Life Sciences, Hubei Normal University, 435002 Huangshi, P.R. China

${ }^{b}$ Institute of Bast Fiber Crops, Chinese Academy of Agricultural Sciences, 410205 Changsha, P.R. China

\begin{abstract}
${ }^{c}$ Hubei Key Laboratory of Mine Environmental Pollution Control and Remediation, School of Environmental Science and Engineering, Hubei Polytechnic University, 435003 Huangshi, P.R. China

${ }^{d}$ Department of Plastic and Cosmetic Surgery, Shenzhen University General Hospital, 518060 Shenzhen, P.R. China
\end{abstract}

\begin{abstract}
Ultrafiltration coupled with liquid chromatography-mass spectrometry (LC-MS) was established to screen xanthine oxidase (XO) inhibitors from Pueraria lobata root extract. Four compounds were screened out and identified as puerarin, daidzin, daidzein and genistein with half-maximal inhibitory concentration $\left(\mathrm{IC}_{50}\right.$ ) values of $30.8,5.31,14.5$ and $3.02 \mu \mathrm{g} \mathrm{mL}^{-1}$ on XO, respectively. The interactions between these compounds and $\mathrm{XO}$ were investigated by fluorescence spectroscopic method. The hydrogen peroxide induced oxidative stress model of human normal gastric epithelial cell lines (GES-1) was used to investigate the protections on injured cell. As a result, four XO inhibitors exhibited protective effects without cytotoxicity. With the increased concentrations of four inhibitors, cell viability was higher with decreased mortality rate, the decrease of superoxide dismutase activity, leakage of lactate dehydrogenase and increase of intracellular superoxide anion production induced by hydrogen peroxide were restrained. It showed that these four XO inhibitors could effectively enhance cell viability and protect injury of GES-1 cells from oxidative stress.
\end{abstract}

Keywords: fluorescence spectra, inhibitor screening, oxidative stress, Pueraria lobata root, xanthine oxidase

\section{Introduction}

Natural extracts with bioactive compounds play an invaluable role in drug discovery process, particularly in the areas of cancer and infectious diseases. ${ }^{1}$ However, owing to the complexities of natural extracts and the difficulties and long-time in separations of ingredients in natural extracts, their application in many related fields was limited. ${ }^{2}$ There is an urgent need to identify novel and active chemotypes as leads for effective drug development. ${ }^{3}$ Ultrafiltration combined with liquid chromatography-mass spectrometry (UF-LC-MS) is one of the most efficient and widely

*e-mail: pingtang@yahoo.com; renlicheng@sina.com;

liuliangliang@caas.cn used techniques for screening of bioactive compounds from complex mixtures like natural extracts. ${ }^{4}$ With the characteristics of simplicity, analysis speed and low cost, UF-LC-MS is regarded as a rapid and high-throughput screening approach to search bioactive components, accelerating the discovery of new active compounds from natural sources. ${ }^{5}$ This method has been adopted to screen enzyme inhibitors, such as the inhibitors of $\alpha$-glucosidase, alcohol dehydrogenase, cyclooxygenase-2, tyrosinase, neuraminidase, and so on.-9

The dried root of Pueraria lobata (Wild.) Ohwi, also called Pueraria lobata root has been used as a well-known conventional herbal medicine for many years around the world. It was used as a food additive and traditional medicine for centuries in China. ${ }^{10}$ The powders of P. lobata 
root were also popular in China as ingredients in drinks and snacks. Isoflavonoids are the major bioactive constituents of $P$. lobata root extract and have many beneficial effects on antioxidation, hypertension and diabetes mellitus. ${ }^{11}$ Xanthine oxidase (XO) is one of critical cytosolic enzymes. It could catalyze the oxidation of hypoxanthine to xanthine and further catalyze the oxidation of xanthine to uric acid. The functional aberrations of XO lead to many diseases like hyperuricemia, gout and other oxidative damages. ${ }^{12}$ Gout is a chronic disease of deposition of monosodium urate crystals caused by increased urate concentrations. Hyperuricemia is the high serum uric acid levels in human body, which is regarded as the major etiologic factor in gout. ${ }^{13}$ Hence, the control of uric acid formation through XO inhibition is useful for preventing gout, while the suppression of $\mathrm{O}^{2-}$ generation is useful for treating oxidative stress as well. ${ }^{14}$ Allopurinol, thiopurinol and 3,5-disubstituted1,2,4-triazoles are traditionally used XO inhibitors. ${ }^{15}$ However, many undesirable side effects limited the usage of them, such as progressive renal failure, skin problems, Stevens-Johnson syndrome and fulminant hepatitis. ${ }^{16-18}$ Hence, more promising XO inhibitors from natural products with fewer adverse effects and higher therapeutic activity are needed. ${ }^{19,20}$ Our preliminary in vitro screening revealed potent XO inhibitory activity of $P$. lobata root extract, which was supported by other literature. ${ }^{21}$ Nevertheless, it is still unclear which compounds in P. lobata root are the active ingredients. Therefore, it was necessary to find the active ingredients in P. lobata root that contributed to XO inhibition.

Oxidative stress is defined by an imbalance between increased levels of reactive oxygen species (ROS) and a low activity of antioxidant mechanisms. It is now recognized to play a central role in the pathophysiology of many different disorders. ${ }^{22}$ Oxidative stress can lead to the modification of cellular proteins, lipids and deoxyribonucleic acid (DNA). Besides, the accumulation of ROS is closely connected to ageing and life span. ${ }^{23}$

In our current work, an efficient method for screening XO inhibitors from extracts of $P$. lobata root was developed by UF-LC-MS. Four compounds with XO binding activity were identified and XO inhibitory activities of these "hits" were verified by measuring half-maximal inhibitory concentration $\left(\mathrm{IC}_{50}\right)$ values. The inhibition and antioxidant properties of these compounds could be supported by other references. ${ }^{24-26}$ Although these compounds were reported before, it was still meaningful to find how they interact with XO and if they have more bioactivities in cells. Based on these, the interactions between four inhibitors and XO were investigated by fluorescence spectroscopic methods, and the protection of four inhibitors on hydrogen peroxide $\left(\mathrm{H}_{2} \mathrm{O}_{2}\right)$ induced oxidative stress model of human normal gastric epithelial cell lines (GES-1 cells) was conducted by evaluating cell viability, intracellular ROS, superoxide dismutase (SOD), lactate dehydrogenase (LDH) release and apoptosis assays. Our studies would provide more experimental evidences for application of $P$. lobata root extract in $\mathrm{XO}$ inhibition and oxidative stress protection.

\section{Experimental}

\section{Materials}

XO powder was purchased from Yuanye Biotechnology Co. (Shanghai, China). P. lobata root was bought from Laobaixing Pharmacy (Changsha, China). Acetonitrile in high-performance liquid chromatography (HPLC) grade was purchased from Merck KGaA (Darmstadt, Germany). Ultrapure water (18.2 $\mathrm{M} \Omega \mathrm{cm}$ resistivity) was obtained from an ELGA water purification system (ELGA Berkefeld, Veolia, Frankfurt, Germany). All other chemicals were analytical grade and purchased from Sinopharm Chemical Reagent Co., Ltd. (Shanghai, China).

\section{Preparation of $P$. lobata root extract}

P. lobata root was firstly powdered and stored at $4{ }^{\circ} \mathrm{C}$. Microwave assisted extraction was used for the extraction of $P$. lobata root following the procedures in literature ${ }^{27}$ with some modifications. Briefly, $30.0 \mathrm{~g}$ of powders were weighted and transferred into a beaker containing $200 \mathrm{~mL}$ of ethanol solution $\left(90 \%, \mathrm{v} \mathrm{v}^{-1}\right)$. The solution was extracted for 6 min in microwave oven at $60 \%$ power. After three times extraction, the solvents were combined and evaporated with rotary evaporator under vacuum. Finally, $2.08 \mathrm{~g}$ of residues were redissolved in water and stored at $4{ }^{\circ} \mathrm{C}$.

\section{Inhibition assay}

Firstly, $20 \mu \mathrm{L}$ of XO solution $\left(1 \mathrm{mg} \mathrm{mL}^{-1}\right)$ and sample (or blank) were mixed in a quartz cuvette. ${ }^{28}$ Then, $1 \mathrm{~mL}$ of xanthine solution $\left(1 \mathrm{mg} \mathrm{mL}^{-1}\right)$ was added to start enzymatic reaction. The cuvette was rapidly moved into an UV-Vis Spectrophotometer (UV2700, Shimadzu, Kyoto, Japan) and the absorbance at $295 \mathrm{~nm}$ was monitored. The same amount of water was used as blank instead of samples under the same conditions. The inhibition of XO could be calculated using the following formula:

$\operatorname{Inhibition}(\%)=\left(1-\Delta \mathrm{A}_{\mathrm{s}} / \Delta \mathrm{A}_{\mathrm{b}}\right) \times 100$

where $\Delta \mathrm{A}_{\mathrm{s}}$ and $\Delta \mathrm{A}_{\mathrm{b}}$ are the increase of absorbance for sample and blank, respectively. The inhibition of sample 
was expressed as the concentration of sample needed to inhibit $50 \%$ of enzymatic activity $\left(\mathrm{IC}_{50}\right)$. All the assays were operated with three replicates.

\section{Screening of XO inhibitors}

The same volume of XO solution $\left(250 \mu \mathrm{L}, 0.75 \mathrm{mg} \mathrm{mL}^{-1}\right)$ and $P$. lobata root extract $\left(250 \mu \mathrm{L}, 100 \mathrm{mg} \mathrm{mL}^{-1}\right)$ were mixed in a tube and incubated at $25^{\circ} \mathrm{C}$ for 30 min under shaking with a thermostatic oscillator. After incubation, the mixture was transferred into an ultrafiltration filter (YM-30, the molecular weight cut off is $10 \mathrm{kDa}$ ) and centrifuged at $13000 \mathrm{rpm}$ for $20 \mathrm{~min}$ at $4{ }^{\circ} \mathrm{C}$. The filtrate was decanted, and the enzyme and binders were retained by the membrane. In order to remove unspecific binding, $500 \mu \mathrm{L}$ of water was added into the filter and the filter was centrifuged at the same conditions. Moreover, $250 \mu \mathrm{L}$ of $80 \%$ methanol solution was added into the filter to elute binders from enzymes and the filter was centrifuged at $13000 \mathrm{rpm}$ for $20 \mathrm{~min}$ at $4{ }^{\circ} \mathrm{C}$. Finally, the filtrate was collected and analyzed by HPLC and LC-MS. The control experiment was carried out in the same condition with denatured enzyme after high temperature processing as a substitution.

HPLC analysis and identification of screened compounds

Qualitative analysis and binding calculation of samples were completed by HPLC analysis on an Agilent 1260 HPLC system (Agilent Technologies, Santa Clara, CA, USA) equipped with a $\mathrm{C}_{18}$ reverse phase column (Waters $\mathrm{Xbridge}^{\mathrm{TM}}, 250 \times 4.6 \mathrm{~mm}$ inner diameter, $5 \mu \mathrm{m}$, Milford, MA, USA). A gradient elution program consisting of two mobile phases (A: water containing $0.1 \%$ acetic acid, $\mathrm{B}$ : acetonitrile) was used as follows: $0-10 \mathrm{~min}, 10 \% \mathrm{~B}$ and $10-40 \mathrm{~min}, 10-55 \% \mathrm{~B}$. The flow rate was $0.8 \mathrm{~mL} \mathrm{~min}^{-1}$ and the column temperature was $25^{\circ} \mathrm{C}$. $5.0 \mu \mathrm{L}$ of sample was injected after filtration using a $0.45 \mu \mathrm{m}$ membrane. The chromatogram was recorded at $254 \mathrm{~nm}$ and the UV spectrum of each peak was recorded from 190 to $400 \mathrm{~nm}$.

The chemical identification of screened compounds was conducted by LC-MS on an Agilent 6460 Triple Quadrupole LC-MS system (Agilent Technologies Inc., Santa Clara, CA, USA). The HPLC conditions were the same with the above conditions. An electron spray ionization (ESI) source was used in both positive and negative ionization modes. The mass detection mode was set at full-scan mode from $\mathrm{m} / \mathrm{z}, 100$ to 1000 .

\section{XO fluorescence quenching}

The fluorescence spectra of XO and the quenching of samples were performed according to procedures reported by previous literatures. ${ }^{29,30}$ Various volumes of sample $\left(0-100 \mu \mathrm{L}, 1.0 \mathrm{mmol} \mathrm{L}^{-1}\right.$ in methanol) were mixed with $2.0 \mathrm{~mL}$ of $\mathrm{XO}$ solution $\left(1.0 \mu \mathrm{mol} \mathrm{\textrm {L } ^ { - 1 }}\right.$ in phosphate buffered saline, PBS). After incubated at $25^{\circ} \mathrm{C}$ for $5 \mathrm{~min}$, the fluorescence emission spectra of samples were recorded from 300 to $400 \mathrm{~nm}$ under an excitation wavelength at $280 \mathrm{~nm}$ using a fluorometer (Hitachi F-7000, Tokyo, Japan). The fluorescence quenchings of XO with samples were calculated by Stern-Volmer formula shown below: ${ }^{31}$

$\mathrm{F}_{0} / \mathrm{F}=1+\mathrm{K}_{\mathrm{q}} \tau_{0}[\mathrm{Q}]=1+\mathrm{K}_{\mathrm{sv}}[\mathrm{Q}]$

where $\mathrm{F}_{0}$ is the fluorescence intensity of $\mathrm{XO}$ at $335 \mathrm{~nm}$, $\mathrm{F}$ is the fluorescence intensity at $335 \mathrm{~nm}$ in the presence of sample, $\mathrm{K}_{\mathrm{q}}$ is the quenching rate constant, $\tau_{0}$ is the average lifetime (6.2 ns), [Q] is the concentration of sample, and $\mathrm{K}_{\mathrm{sv}}$ is the Stern-Volmer quenching constant.

The relationship between fluorescence quenching intensity at $335 \mathrm{~nm}$ and the concentration of sample was described by the binding constant formula:

$\log _{10}\left[\left(\mathrm{~F}_{0}-\mathrm{F}\right) / \mathrm{F}\right]=\log _{10} \mathrm{~K}_{\mathrm{a}}+\operatorname{nlog}_{10}[\mathrm{Q}]$

where $\mathrm{K}_{\mathrm{a}}$ is the binding constant, and $\mathrm{n}$ is the number of binding sites per enzyme molecule. All the samples showed no emission spectra in the scanned range under excitation.

Effects of screened compounds on the oxidative stress of GES-1

\section{Cell culture}

The human GES-1 cell line was purchased from Yuxi Biotechnology Co., Ltd. (Jiangyin, China) and cultured in Dulbecco's modified Eagle medium containing 10\% fetal bovine serum (Gibco, Thermo Fisher Scientific Inc., Waltham, MA, USA), $1 \%$ penicillin and $1 \%$ streptomycin (Yuxi Biotechnology, Jiangyin, China) with a humidified $5 \% \mathrm{CO}_{2}$ atmosphere at $37^{\circ} \mathrm{C}$ in a cell incubator.

\section{Cytotoxicity assay}

Cell counting kit-8 (CCK-8) assay was used to estimate the cytotoxicity induced by $\mathrm{H}_{2} \mathrm{O}_{2}$ on GES- 1 in the presence of four screened compounds. GES-1 cell suspension ( 2 to $3 \times 10^{5}$ cells well $^{-1}$ ) was inoculated into 96 -well plates and preincubated overnight. For experiments, GES-1 cells were exposed to $250 \mu \mathrm{mol} \mathrm{L}-1 \mathrm{H}_{2} \mathrm{O}_{2}$ in the presence of 10 ,

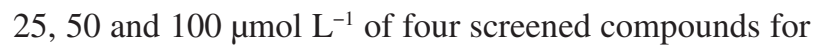
$72 \mathrm{~h}$. After exposure, $10 \mu \mathrm{L}$ of CCK- 8 reaction solution was added to each well and the plate was incubated for $2 \mathrm{~h}$ in the incubator. Finally, the absorbance at $450 \mathrm{~nm}$ of 
each well was measured with a microplate reader (Epoch, BioTek Instruments Inc., Winooski, VT, USA). The GES-1 cells without exposure of $\mathrm{H}_{2} \mathrm{O}_{2}$ and compounds were set as controls.

\section{Measurement of intracellular ROS and SOD}

As described in previous literature, ${ }^{32}$ the intracellular superoxide was estimated by using a dihydroethidium probe (DHE; Beyotime Institute of Biotechnology, Nantong, China) with modifications. GES-1 cells were exposed to $250 \mu \mathrm{mol} \mathrm{L}^{-1} \mathrm{H}_{2} \mathrm{O}_{2}$ in the presence of $10,25,50$ and $100 \mu \mathrm{mol} \mathrm{L}{ }^{-1}$ of four screened compounds for $72 \mathrm{~h}$. After exposure, cells were incubated with medium containing $5 \mu \mathrm{mol} \mathrm{L}{ }^{-1}$ of DHE for $30 \mathrm{~min}$ to determine ROS production in red color. And then, the fluorescences at $600 \mathrm{~nm}$ of cells were read under the excitation light at $530 \mathrm{~nm}$ by a microplate reader (Epoch, BioTek, USA).

The activities of SOD were determined by using commercially available kit (Total Superoxide Dismutase Assay Kit with WST-8, Beyotime Institute of Biotechnology, China) complied with the manufacturer's instructions. ${ }^{33,34}$ Briefly, $20 \mu \mathrm{L}$ of sample solution was mixed with $160 \mu \mathrm{L}$ of WST-8/enzyme working solution (containing $151 \mu \mathrm{L}$ SOD assay buffer, $8 \mu \mathrm{L}$ WST- 8 and $1 \mu \mathrm{L}$ enzyme solution) and $20 \mu \mathrm{L}$ of reaction triggering working solution $(1 \mu \mathrm{L}$ of reaction starting solution diluted with $39 \mu \mathrm{L}$ SOD buffer). After incubated at $37^{\circ} \mathrm{C}$ for $30 \mathrm{~min}$, the absorbance values of samples were recorded at $450 \mathrm{~nm}$ using a microplate reader (Epoch, BioTek, USA). All the experiments were repeated three times independently.

\section{Measurement of LDH release}

The LDH release from cytoplasm with damaged cell membrane could evaluate the cell membrane integrity. The quantitative analysis of LDH was completed with commercially available LDH Cytotoxicity Assay Kit (Beyotime Institute of Biotechnology, China) according to the manufacturer's instructions. ${ }^{35}$ The GES-1 cells were exposed to $250 \mu \mathrm{mol} \mathrm{L}^{-1} \mathrm{H}_{2} \mathrm{O}_{2}$ in the presence of 10,25 , 50 and $100 \mu \mathrm{mol} \mathrm{L} \mathrm{L}^{-1}$ of four screened compounds for $72 \mathrm{~h}$. After treatment, the plate of cells was centrifuged for $5 \mathrm{~min}$ and the culture medium was gently aspirated. Then, $150 \mu \mathrm{L}$ of LDH release reagents in PBS was added into the cells and incubated for $1 \mathrm{~h}$. Finally, the supernatant culture medium of each cell after $5 \mathrm{~min}$ of centrifugation was transferred for $\mathrm{LDH}$ determination. The LDH activity was determined using a spectrophotometric method monitoring the optical density at $490 \mathrm{~nm}$. $60 \mu \mathrm{L}$ of detection solution was added to the above mentioned supernatant culture medium of each cell. The plate was incubated for $30 \mathrm{~min}$ in dark and the absorbance of each sample was measured. The LDH activity was calculated as the percentage of LDH activity in control group.

\section{GES-1 cell apoptosis measurement}

The GES- 1 cells were exposed to $250 \mu \mathrm{mol} \mathrm{L}^{-1} \mathrm{H}_{2} \mathrm{O}_{2}$ in the presence of $10,25,50$ and $100 \mu \mathrm{mol} \mathrm{L}^{-1}$ of four screened compounds for $72 \mathrm{~h}$. At the end of incubation, the cells were collected and washed twice by cold PBS. For apoptosis assay, the cells were resuspended in $300 \mu \mathrm{L}$ of binding buffer, and were stained with $5 \mu \mathrm{L}$ of annexin V-fluorescein isothiocyanate (V-FITC) and $10 \mu \mathrm{L}$ of propidium iodide (PI) (MultiSciences Biotech Co., Ltd., Hangzhou, China) and left in the dark for $15 \mathrm{~min}$. Apoptosis rate was detected and analyzed with the use of flow cytometry.

\section{Results and Discussion}

\section{Screening of $\mathrm{XO}$ binders from $P$. lobata root extract}

\section{Optimization of HPLC conditions}

P. lobata root contains many kinds of isoflavonoids. ${ }^{33}$ Similar compounds in extracts make the HPLC separation more difficult. In order to optimize the chromatographic conditions for analysis, different gradient elution programs, column temperatures, ratio of acid content, flow rates, injection volume, detection wavelength were all tested. Finally, the HPLC analysis was achieved in 40 min with satisfactory separation of main peaks. The shape and width of peaks in P. lobata root extract were also presented well. The chromatogram of P. lobata root extract was shown in Figure 1.

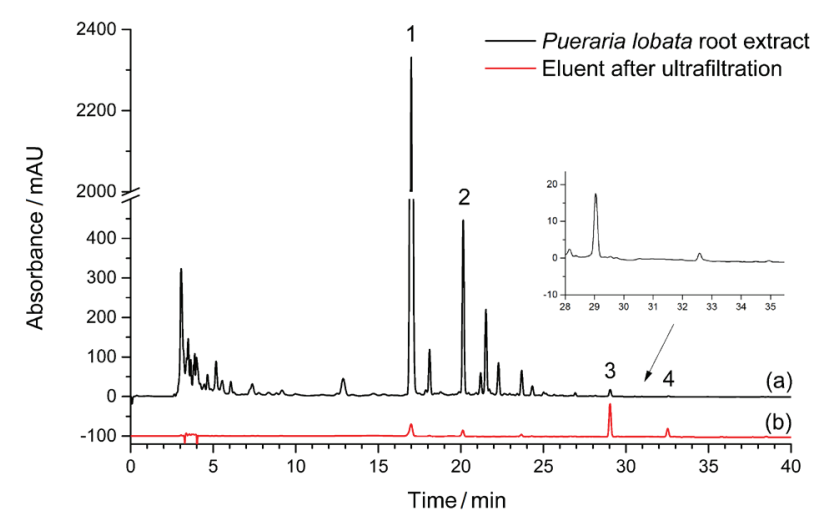

Figure 1. The chromatograms of (a) $P$. lobata root extract and (b) eluent after ultrafiltration.

\section{Screening of $X O$ binders}

The inhibition of $P$. lobata root extract on $\mathrm{XO}$ was conducted before the screening assay. According to our former inhibition test result for plant extracts, P. lobata root extract showed apparent inhibition and the $\mathrm{IC}_{50}$ value 
was $96.0 \mu \mathrm{g} \mathrm{mL}-1$ for water extract. The results indicated that the P. lobata root extract contains XO inhibitors and the following screening and identification of XO inhibitors from extract are worthwhile.

After ultrafiltration and washing procedures, the methanol elute containing XO binders was analyzed by HPLC. The chromatogram of eluent was shown in Figure 1, and four peaks marked with numbers could be clearly found. These four peaks could also be located in the chromatogram of $P$. lobata root extract at the same retention times. The screening with denatured enzyme was conducted as well. The chromatogram of eluent showed no peak appeared in $40 \mathrm{~min}$ analysis (data not shown), which confirmed that four peaks marked with numbers were specifically bound to XO. Therefore, further identification and analysis of these four peaks are needed.

\section{Identification of screened XO binders}

HPLC-MS analysis was carried out to identify these four binders. The structures were finally identified by analyzing and comparing their retention times, UV and MS data with those of authentic samples (Table 1). By analysis of the UV spectra, these compounds showed the maximum absorbance at $255 \mathrm{~nm}$ with a second absorbance around $320 \mathrm{~nm}$, which was the typical spectra of isoflavone derivatives. In both positive and negative modes, the MS spectra of four compounds showed the deprotonated molecular ion $[\mathrm{M}+\mathrm{H}]^{+}$and $[\mathrm{M}-\mathrm{H}]^{-}$at $\mathrm{m} / z, 417$ and 415 for compound $\mathbf{1}$ and $\mathbf{2}, \mathrm{m} / \mathrm{z}, 255$ and 253 for compound $\mathbf{3}$ and $m / z 271$ and 269 for compound 4. Moreover, the MS spectrum of compound 2 showed $\left[\mathrm{M}+\mathrm{CH}_{3} \mathrm{COOH}-\mathrm{H}\right]^{-}$ at $m / z, 475$ and the MS spectrum of compound $\mathbf{3}$ showed $[2 \mathrm{M}-\mathrm{H}]^{-}$at $m / z, 507$ in the negative mode. According to the result of comparing retention times and MS spectra of authentic references with that of samples, these four compounds were identified as puerarin (1), daidzin (2), daidzein (3) and genistein (4) (the structures were shown in Figure 2). ${ }^{36-38}$ The chromatograms of four authentic references were shown in Figure 3 together with that of P. lobata root extract. It could be found that their retention times were the same as those in the extract, which showed the identification of these four peaks was credible.

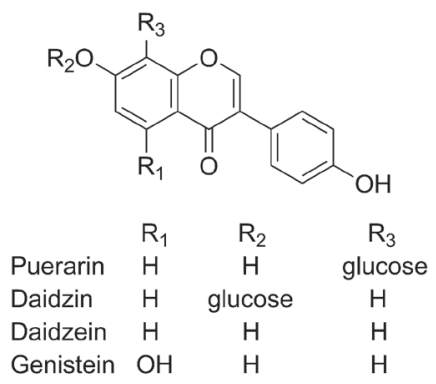

Figure 2. The chemical structures of four screened binders: puerarin, daidzin, daidzein and genistein.

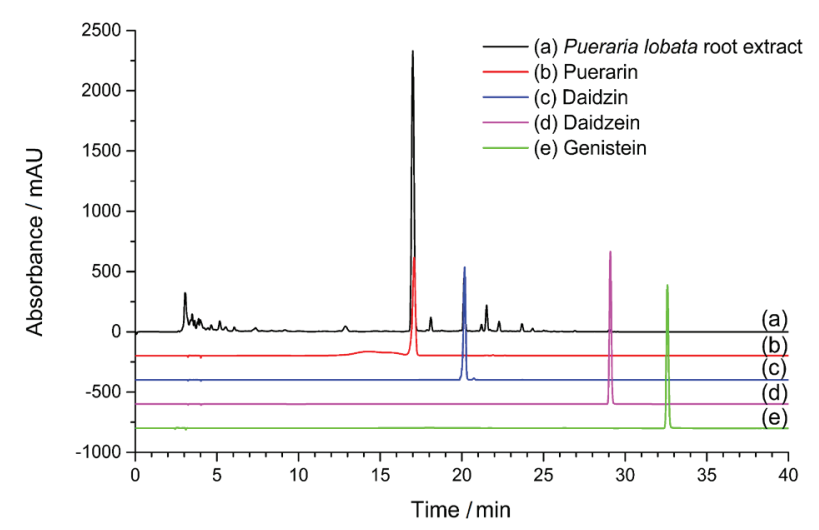

Figure 3. The chromatograms of (a) $P$. lobata root extract and authentic references: (b) puerarin; (c) daidzin; (d) daidzein and (e) genistein.

\section{Inhibition verifications of screened XO binders}

Since the screened four XO binders were identified, the inhibitions on $\mathrm{XO}$ of puerarin, daidzin, daidzein and genistein were also tested. As a result, all four compounds

Table 1. The identification information of four screened binders

\begin{tabular}{|c|c|c|c|c|c|c|}
\hline No. & Identification & $t_{R} / \min$ & Mw & Proposed ion $(\mathrm{m} / \mathrm{z})$ & & $\mathrm{UV} \lambda \max / \mathrm{nm}$ \\
\hline 1 & puerarin & 17.0 & 416 & $\begin{array}{l}{[\mathrm{M}+\mathrm{H}]^{+}} \\
{[\mathrm{M}-\mathrm{H}]^{-}}\end{array}$ & $\begin{array}{l}417 \\
415\end{array}$ & 254,310 \\
\hline 2 & daidzin & 20.1 & 416 & $\begin{array}{c}{[\mathrm{M}-\mathrm{H}]^{-}} \\
{\left[\mathrm{M}+\mathrm{CH}_{3} \mathrm{COOH}-\mathrm{H}\right]^{-}} \\
{[\mathrm{M}+\mathrm{H}]^{+}} \\
\end{array}$ & $\begin{array}{l}415 \\
475 \\
417 \\
\end{array}$ & 254,305 \\
\hline 3 & daidzein & 29.0 & 254 & $\begin{array}{c}{[\mathrm{M}+\mathrm{H}]^{+}} \\
{[\mathrm{M}-\mathrm{H}]^{-}} \\
{[2 \mathrm{M}-\mathrm{H}]^{-}}\end{array}$ & $\begin{array}{l}255 \\
253 \\
507\end{array}$ & 254,310 \\
\hline 4 & genistein & 32.6 & 270 & $\begin{array}{l}{[\mathrm{M}+\mathrm{H}]^{+}} \\
{[\mathrm{M}-\mathrm{H}]^{-}}\end{array}$ & $\begin{array}{l}271 \\
269\end{array}$ & 254,330 \\
\hline
\end{tabular}

$\mathrm{t}_{\mathrm{R}}$ : retention time; Mw: molecular weight; $\mathrm{UV} \lambda \max$ : maximum wavelength in ultraviolet (UV) spectrum. 
exhibited inhibitions on XO. The $\mathrm{IC}_{50}$ values of puerarin, daidzin, daidzein and genistein were 30.8, 5.31, 14.5 and $3.02 \mu \mathrm{g} \mathrm{mL} \mathrm{m}^{-1}$, respectively. The inhibition of these four compounds on $\mathrm{XO}$ were also reported by other researchers. ${ }^{4,25,39}$ These results demonstrated that the screened compounds actually have inhibitory effects on $\mathrm{XO}$ and proved that the proposed method is effective in respect of screening enzyme binders with inhibition activities from mixture.

\section{Fluorescent quenching of $\mathrm{XO}$}

\section{Quenching effects of four screened inhibitors}

Fluorescence quenching is a kind of bioanalytical and diagnostic tool to study the interaction of biological macromolecules with small molecules. ${ }^{31}$ As shown in Figure 4, XO showed the fluorescence emission peak at $335 \mathrm{~nm}$ and the fluorescence intensities reduced apparently when four inhibitors were added into XO solution. Considering the quenching effects of four inhibitors, the Stern-Volmer plots for XO fluorescence quenching were calculated and plotted to gain more quenching information.
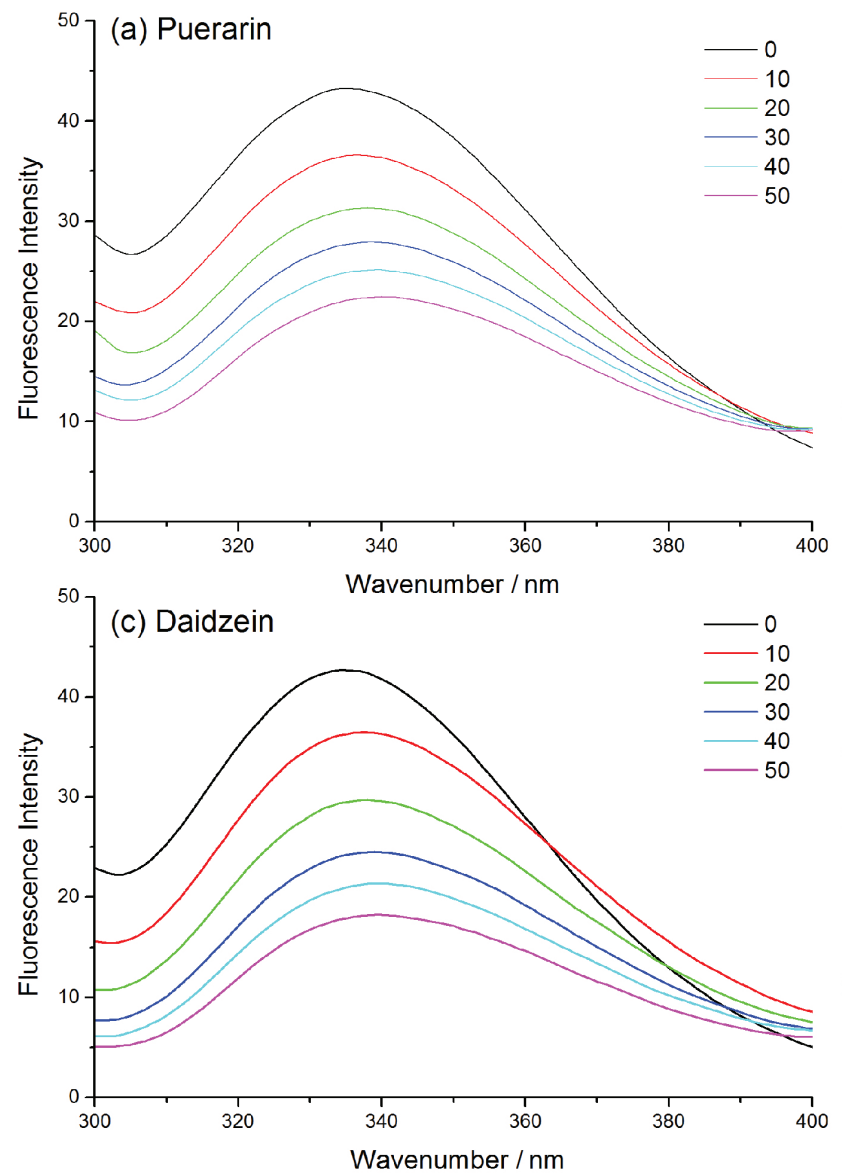

The calculated binding parameters were demonstrated in Table 2 and the Stern-Volmer plots were displayed in Figure 5a. The Stern-Volmer plots of puerarin, daidzin, daidzein and genistein were linear and the fitting degrees were more than 0.988 , which reflected the calculations of $\mathrm{K}_{\mathrm{sv}}$ and $\mathrm{K}_{\mathrm{q}}$ were acceptable. The linear Stern-Volmer plots indicated a single way of quenching, dynamic quenching or static quenching, which played a key role in the binding between enzyme and binders. ${ }^{40} \mathrm{~K}_{\mathrm{q}}$ is a factor indicating the efficiency of quenching and the accessibility of fluorophores. When the value of $\mathrm{K}_{\mathrm{q}}$ is apparently greater than $2.0 \times 10^{10} \mathrm{~L} \mathrm{~mol}^{-1} \mathrm{~s}^{-1}$, the quenching could be considered as a static quenching..$^{41}$ Based on this principle, as the values of $\mathrm{K}_{\mathrm{q}}$ for these four inhibitors were much greater than $2.0 \times 10^{10} \mathrm{~L} \mathrm{~mol}^{-1} \mathrm{~s}^{-1}$, their quenching modes could be considered as static quenchings.

\section{Binding parameters}

For static quenching, the binding parameters (the number of binding sites per protein molecule (n) and binding constants $\left(\mathrm{K}_{\mathrm{a}}\right)$ ) and the double-logarithm curves could be calculated according to equation 3 and plotted
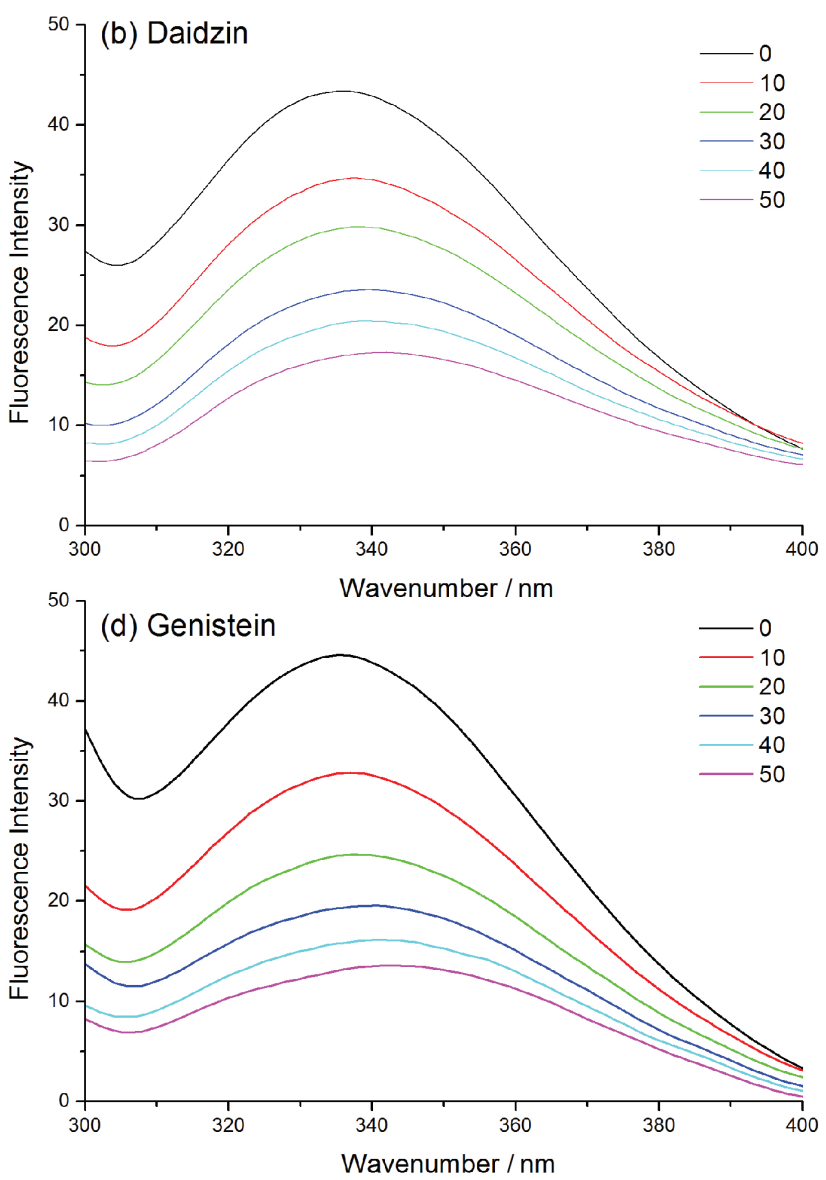

Figure 4. The quenching effects of (a) puerarin; (b) daidzin; (c) daidzein and (d) genistein on $\mathrm{XO}$ fluorescence spectra. $\lambda$ ex $=280 \mathrm{~nm}$; $1.0 \mu \mathrm{mol} \mathrm{L}^{-1} \mathrm{XO}$; the addition of inhibitors was 10, 20, 30, 40 and $50 \mu \mathrm{mol} \mathrm{L} \mathrm{L}^{-1}$. 
Table 2. Affinity constants of puerarin, daidzin, daidzein and genistein for XO

\begin{tabular}{|c|c|c|c|c|c|c|c|}
\hline No. & Compound & $\mathrm{K}_{\mathrm{q}} \times 10^{13}$ & $\mathrm{~K}_{\mathrm{sv}} \times 10^{5}$ & $\mathrm{R}^{2}$ & $\log _{10} \mathrm{~K}_{\mathrm{a}}$ & $\mathrm{n}$ & $\mathrm{R}^{2}$ \\
\hline 1 & puerarin & 0.305 & 0.189 & 0.999 & 4.31 & 1.01 & 0.999 \\
\hline 2 & daidzin & 0.505 & 0.313 & 0.988 & 5.08 & 1.14 & 0.988 \\
\hline 3 & daidzein & 0.452 & 0.280 & 0.992 & 5.65 & 1.28 & 0.999 \\
\hline 4 & genistein & 0.785 & 0.487 & 0.994 & 5.44 & 1.18 & 0.999 \\
\hline
\end{tabular}

$\mathrm{K}_{\mathrm{q}}$ : quenching rate constant; $\mathrm{K}_{\mathrm{sv}}:$ Stern-Volmer quenching constant; $\mathrm{R}^{2}$ : fitting degree; $\mathrm{K}_{\mathrm{a}}$ : binding constant; $\mathrm{n}$ : number of binding sites per protein molecule.
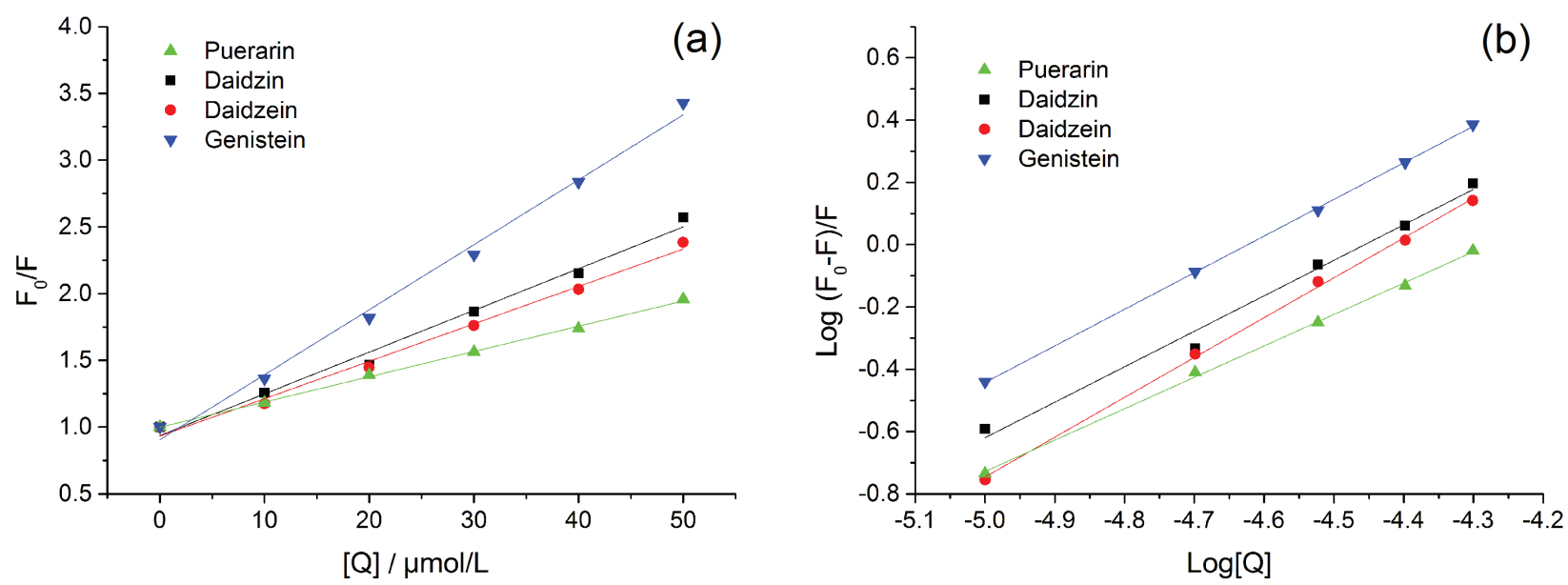

Figure 5. (a) The Stern-Volmer plots for XO fluorescence quenching by puerarin, daidzin, daidzein and genistein; (b) plots of $\log \left[\left(\mathrm{F}_{0}-\mathrm{F}\right) / \mathrm{F}\right]$ versus $\log [\mathrm{Q}]$ for puerarin, daidzin, daidzein and genistein.

for visual presentation. The values of $\mathrm{K}_{\mathrm{a}}, \mathrm{n}$ and the degrees of fitting were shown in Table 2, and the plots of $\log \left[\left(\mathrm{F}_{0}-\mathrm{F}\right) / \mathrm{F}\right]$ versus $\log [\mathrm{Q}]$ for each inhibitor were shown in Figure 5b. As a result, the fitting degrees of these calculations were higher than 0.988 and the curves were linear, indicating related calculations were acceptable. ${ }^{42}$ Among the different binding constants of four inhibitors, daidzein showed the maximum value of $\log _{10} \mathrm{~K}_{\mathrm{a}}(5.65)$ and puerarin showed the minimum value of $\log _{10} \mathrm{~K}_{\mathrm{a}}$ (4.31). Accordingly, it could be assumed that daidzein exhibited the strongest binding capacity of these four inhibitors.

Effects of screened inhibitors on the oxidative stress of GES-1

\section{Cytotoxicity of GES-1}

To evaluate the protective roles of four screened inhibitors on $\mathrm{H}_{2} \mathrm{O}_{2}$-induced cytotoxicity, GES- 1 cells were employed for this investigation. According to CCK-8 assay results shown in Figure 6a, the cell viability decreased markedly to $75.0 \%$ in the presence of $250 \mu \mathrm{mol} \mathrm{L}^{-1} \mathrm{H}_{2} \mathrm{O}_{2}$ for $72 \mathrm{~h}$. However, the existences of puerarin, daidzin, daidzein and genistein (ranging from 10, 25, 50 to $100 \mu \mathrm{mol} \mathrm{L}{ }^{-1}$ ) in the incubation significantly increased the cell viability. Moreover, the protective effect increased with the concentration enhancing and the optimum concentration could be observed for each inhibitor. In order to exclude the cytotoxicities of four compounds, the control experiments were also conducted and shown in Figure 6b. It could be seen that there was a small decrease of cell viability for each compound at the same concentrations. These results showed that puerarin, daidzin, daidzein and genistein were able to ameliorate $\mathrm{H}_{2} \mathrm{O}_{2}$-induced oxidative damage of GES- 1 cells without additional cytotoxicities.

\section{Intracellular ROS and SOD}

The effectiveness of four screened inhibitors on the $\mathrm{H}_{2} \mathrm{O}_{2}$-induced intracellular ROS level was investigated using DHE probes (Figure 7a). The quantitative assay showed that intracellular ROS after $\mathrm{H}_{2} \mathrm{O}_{2}$-induced treatment was obviously higher than that in control group. Remarkably, the addition of puerarin, daidzin, daidzein and genistein respectively decreased the ROS level in a dose-dependent manner. The lowest relative production of ROS was observed in the $100 \mu \mathrm{mol} \mathrm{L}{ }^{-1}$ of puerarin, daidzin, daidzein and genistein after incubation of $72 \mathrm{~h}$, and the levels of SOD mostly reduced to a normal level.

The expression and activity of SOD are important in modulating ROS level by scavenging free radicals in cells. ${ }^{43}$ It could be seen that $\mathrm{H}_{2} \mathrm{O}_{2}$ prominently impeded the activity 

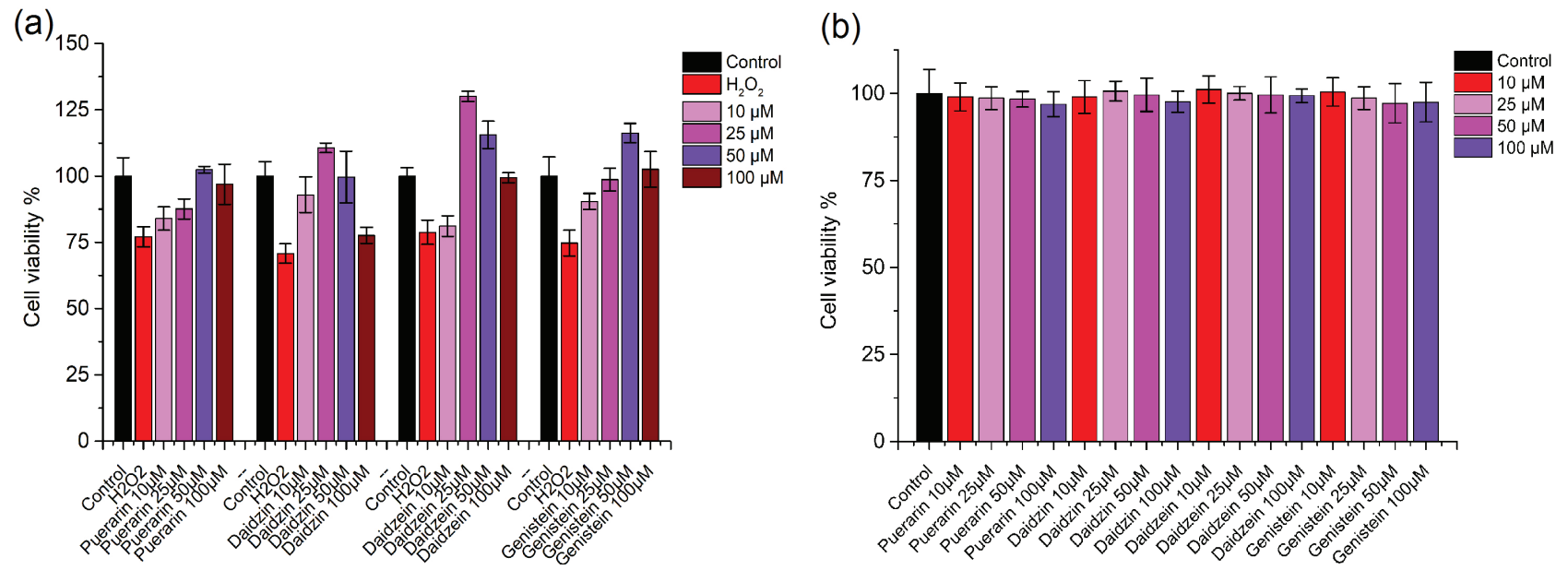

Figure 6. Effect of puerarin, daidzin, daidzein and genistein on cell viability in (a) $\mathrm{H}_{2} \mathrm{O}_{2}$-induced GES-1 cell and (b) normal GES-1 cell.

(a)

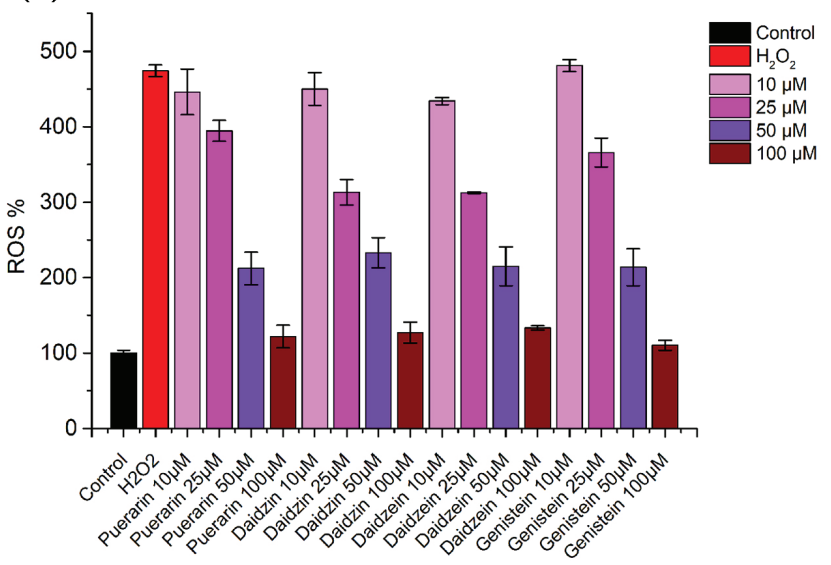

(b)

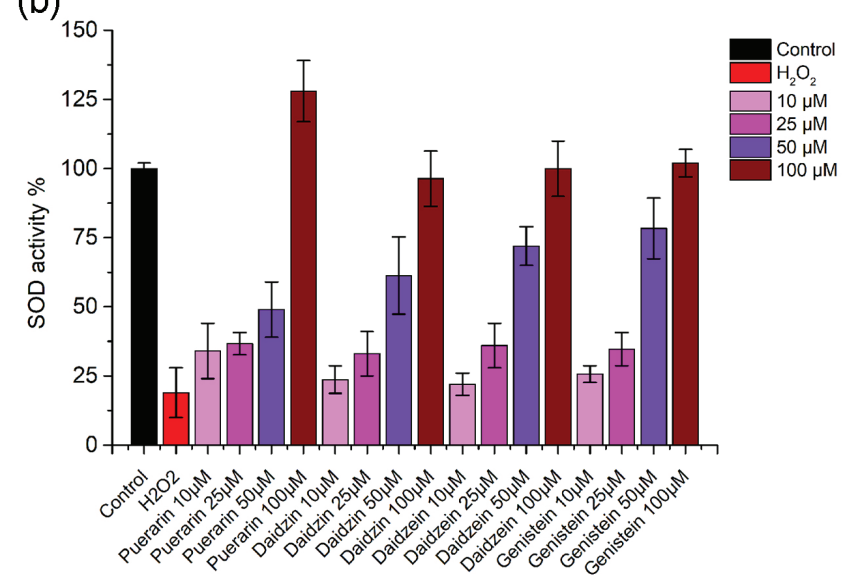

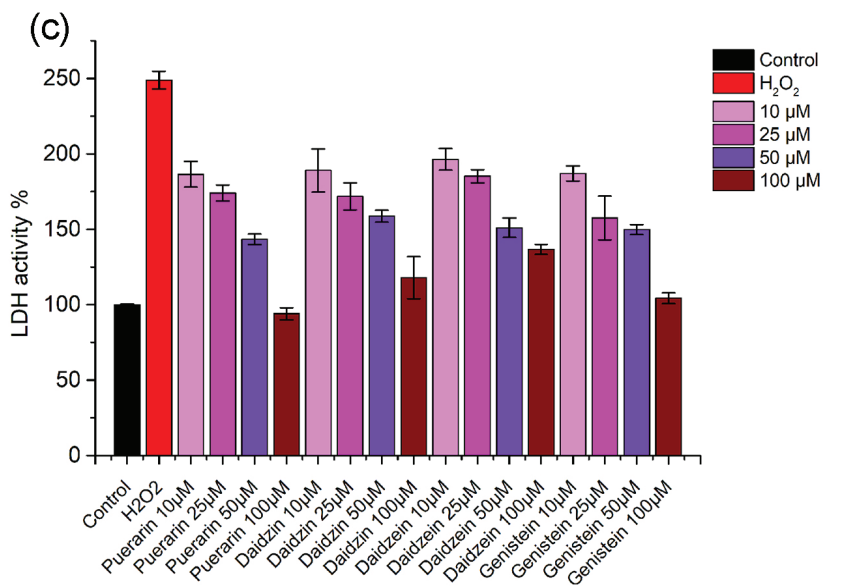

Figure 7. Effect of puerarin, daidzin, daidzein and genistein on (a) intracellular ROS; (b) intracellular SOD activity and (c) LDH release in $\mathrm{H}_{2} \mathrm{O}_{2}$-induced GES-1 cell.

of SOD compared to the control group (Figure 7b) ${ }^{44}$ However, puerarin, daidzin, daidzein and genistein restored the decrease of SOD activity in a dose-dependent manner under oxidative stress. These results suggested that puerarin, daidzin, daidzein and genistein protected the antioxidant capacity of GES-1 by scavenging ROS accumulation induced by $\mathrm{H}_{2} \mathrm{O}_{2}$ and activating antioxidant enzymes.

\section{$\mathrm{LDH}$ release}

The concentration of LDH released from cytoplasm could reflect the cell membrane integrity. As shown in 
Figure $7 \mathrm{c}$, after $72 \mathrm{~h}$ exposure of $250 \mu \mathrm{mol} \mathrm{L}-1 \mathrm{H}_{2} \mathrm{O}_{2}$ for GES-1, the LDH concentrations in medium were nearly 2.5 times higher than that of control group. Then the release of LDH was significantly decreased when cells were incubated with puerarin, daidzin, daidzein and genistein together with $\mathrm{H}_{2} \mathrm{O}_{2}$, and the decrease is in a dose-dependent manner. When the concentration of four inhibitors reached $100 \mu \mathrm{mol} \mathrm{L} \mathrm{L}^{-1}$, no difference in LDH release levels was detected compared to control group. It indicated that puerarin, daidzin, daidzein and genistein had obvious protective effects against $\mathrm{H}_{2} \mathrm{O}_{2}$-induced cell membrane damage in GES- 1 .

\section{Assay of cell apoptosis}

To further investigate the effects of puerarin, daidzin, daidzein and genistein on cell apoptosis, the apoptotic rate of GES-1 was measured by flow cytometry (Figure 8). The percentages of normal, early-apoptotic, late-apoptotic and

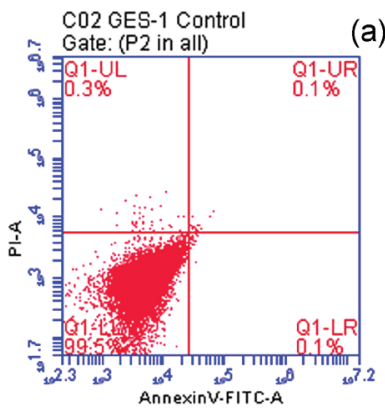

(a) $\quad \mathrm{B} 10 \mathrm{H} 2 \mathrm{O} 2$

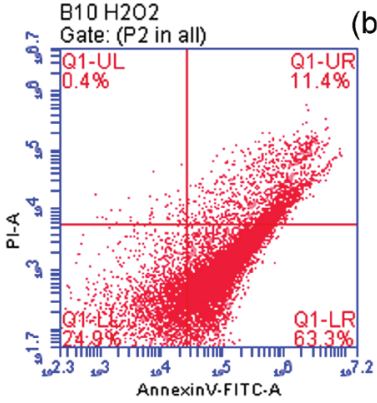

F03 Puerain $100 \mathrm{uM}+\mathrm{H} 2 \mathrm{O} 2$

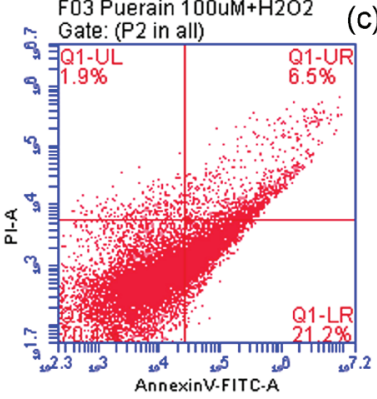

(c)
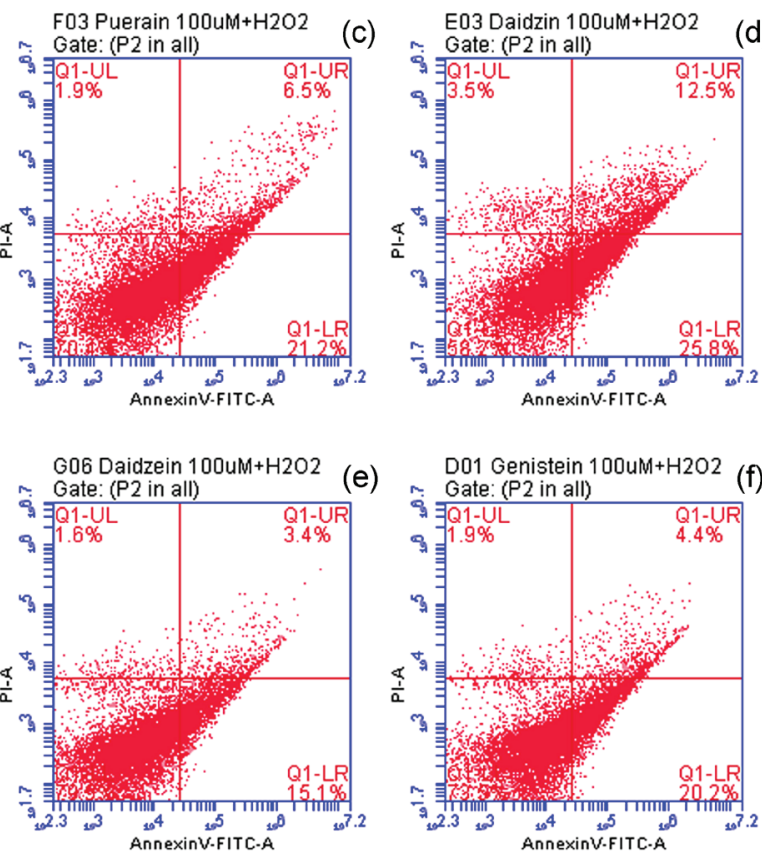

(e)

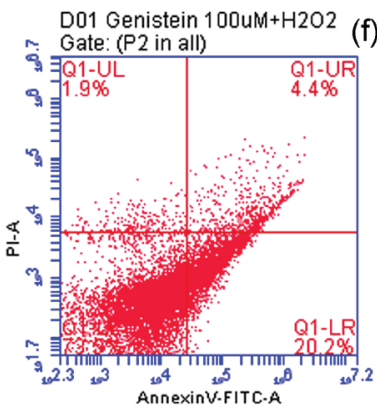

Figure 8. Effects of puerarin, daidzin, daidzein and genistein on apoptosis of GES-1 cells. (a) Control cell; (b) $250 \mu \mathrm{mol} \mathrm{L}^{-1} \mathrm{H}_{2} \mathrm{O}_{2}$; (c) $100 \mu \mathrm{mol} \mathrm{L}^{-1}$ of puerarin and $\mathrm{H}_{2} \mathrm{O}_{2}$; (d) $100 \mu \mathrm{mol} \mathrm{L}-1$ of daidzin and $\mathrm{H}_{2} \mathrm{O}_{2}$; (e) $100 \mu \mathrm{mol} \mathrm{L}^{-1}$ of daidzein and $\mathrm{H}_{2} \mathrm{O}_{2}$; (f) $100 \mu \mathrm{mol} \mathrm{L}-1$ of genistein and $\mathrm{H}_{2} \mathrm{O}_{2}$. necrotic cells in each group were calculated. After $72 \mathrm{~h}$ exposure of $250 \mu \mathrm{mol} \mathrm{L}{ }^{-1} \mathrm{H}_{2} \mathrm{O}_{2}$, rather higher percentages of early and late apoptotic cells were observed compared with the control group (increased from 0.1 to $11.4 \%$ and 0.1 to $63.3 \%$, respectively). However, puerarin, daidzin, daidzein and genistein treated cells exhibited effects on the induction of cell apoptosis in a dose-dependent manner. Both percentages of early and late apoptotic cells were reduced with the increasing concentrations of four inhibitors. As shown in Figure 8 and Table 3, when treated with $100 \mu \mathrm{mol} \mathrm{L} \mathrm{L}^{-1}$ of puerarin, daidzin, daidzein and genistein in the presence of $\mathrm{H}_{2} \mathrm{O}_{2}$, the percentages of early and total apoptotic cells were significantly decreased. Hence, GES-1 cells were protected in the presence of puerarin, daidzin, daidzein and genistein against $\mathrm{H}_{2} \mathrm{O}_{2}$-induced oxidative stress.

Table 3. Apoptosis data of GES-1 cells treated by different concentrations of puerarin, daidzin, daidzein and genistein

\begin{tabular}{|c|c|c|c|}
\hline Compound & $\begin{array}{c}\text { Concentration / } \\
\left(\mu \mathrm{mol} \mathrm{L} \mathrm{L}^{-1}\right)\end{array}$ & Q1-UR / \% & Q1-LR / \% \\
\hline Control & & 0.1 & 0.1 \\
\hline $\mathrm{H}_{2} \mathrm{O}_{2}$ & 250 & 11.4 & 63.3 \\
\hline \multirow{4}{*}{ Puerarin } & 10 & 11.9 & 56.4 \\
\hline & 25 & 15.6 & 52.9 \\
\hline & 50 & 17.7 & 36.2 \\
\hline & 100 & 6.5 & 21.2 \\
\hline \multirow{4}{*}{ Daidzin } & 10 & 8.4 & 65.2 \\
\hline & 25 & 10.8 & 54.0 \\
\hline & 50 & 11.3 & 44.4 \\
\hline & 100 & 12.5 & 25.8 \\
\hline \multirow{4}{*}{ Daidzein } & 10 & 14.0 & 51.6 \\
\hline & 25 & 10.1 & 37.3 \\
\hline & 50 & 9.6 & 30.1 \\
\hline & 100 & 3.4 & 15.1 \\
\hline \multirow{4}{*}{ Genistein } & 10 & 6.6 & 54.8 \\
\hline & 25 & 9.5 & 44.2 \\
\hline & 50 & 7.7 & 32.0 \\
\hline & 100 & 4.4 & 20.2 \\
\hline
\end{tabular}

Q1-UR: upper right; Q1-LR: lower right

\section{Conclusions}

In this study, four compounds were successfully screened out as XO binders and identified as puerarin, daidzin, daidzein and genistein from P. lobata root extract using established UF-LC-MS method. Their inhibitory activity were confirmed with $\mathrm{IC}_{50}$ values of $30.8,5.31$, 14.5 and $3.02 \mu \mathrm{g} \mathrm{mL}^{-1}$, respectively. Although these four compounds were reported as possessing $\mathrm{XO}$ inhibition 
activity, they were firstly screened out as XO inhibitors from $P$. lobata root extract. In order to get more information on the interaction between inhibitor and enzyme molecules, the fluorescence spectra analyses were accomplished. It showed these compounds quenched the fluorescence intensities of $\mathrm{XO}$ in static quenching mechanism. Daidzein exhibited the strongest binding capacity $\left(\log _{10} \mathrm{~K}_{\mathrm{a}}=5.65\right)$ of these four inhibitors, while puerarin showed the weakest binding capacity $\left(\log _{10} \mathrm{~K}_{\mathrm{a}}=4.31\right)$. Furthermore, the antioxidative and protection effects of compounds on $\mathrm{H}_{2} \mathrm{O}_{2}$-induced GES-1 cells were conducted. Four compounds exhibited apparently protective effects by protecting cell viability, decrease of SOD activity, leakage of LDH and increase of ROS induced by $\mathrm{H}_{2} \mathrm{O}_{2}$. In conclusion, UF-LC-MS exhibited efficiency in screening and identification of enzyme inhibitors from complex mixtures. Puerarin, daidzin, daidzein and genistein showed XO inhibition and they could effectively enhance cell viability and reduce injury of GES-1 cells from oxidative stress. Further research on their bioactivities and the structure activity relationship of these flavonoids should be conducted in future.

\section{Acknowledgments}

This work was supported by the Natural Science Foundation of Hubei Province (grant No. 2019CFB792).

\section{Author Contributions}

Xiaosheng Tang was responsible for the data curation, formal analysis and writing original draft, review and editing; Aiping Xiao for the project administration and writing original draft; Shiyong Mei for the methodology; Ping Tang for the data curation; Licheng Ren for the data curation and writing review and editing; Liangliang Liu for the conceptualization, investigation, writing original draft, review and editing.

\section{References}

1. Martillanes, S.; Rocha-Pimienta, J.; Gil, M. V.; Ayuso-Yuste, M. C.; Delgado-Adámez, J.; Food Chem. 2020, 308, 125633.

2. Lam, K. S.; Trends Microbiol. 2007, 15, 279.

3. Harvey, A. L.; Drug Discovery Today 2008, 13, 894.

4. Liu, L. L.; Xiao, A.; Ma, L.; Li, D.; J. Braz. Chem. Soc. 2017, 28, 360 .

5. Yang, Z.; Zhang, Y.; Sun, L.; Wang, Y.; Gao, X.; Cheng, Y.; Anal. Chim. Acta 2012, 719, 87.

6. Song, H.; Zhang, H.; Fu, Y.; Mo, H.; Zhang, M.; Chen, J.; Li, P.; J. Chromatogr. B 2014, 961, 56.
7. Xiao, S.; Yu, R.; Ai, N.; Fan, X.; J. Pharm. Biomed. Anal. 2015, 104, 67.

8. Yang, D.; Zhao, J.; Liu, S.; Song, F.; Liu, Z.; Anal. Methods 2014, 6, 3353.

9. Chen, M.; Liu, L. L.; Chen, X. Q.; J. Sep. Sci. 2014, 37, 1546.

10. Fan, J.-P.; Cao, J.; Zhang, X.-H.; Huang, J.-Z.; Kong, T.; Tong, S.; Tian, Z.-Y.; Xie, Y.-L.; Xu, R.; Zhu, J.-H.; Food Chem. 2012, 135, 2299.

11. Li, Y.; Song, Y. Q.; Zhu, C. Y.; Chin. Herb. Med. 2019, 11, 78.

12. Kaur, G.; Singh, J. V.; Gupta, M. K.; Bhagat, K.; Gulati, H. K.; Singh, A.; Bedi, P. M. S.; Singh, H.; Sharma, S.; Med. Chem. Res. 2020, 29, 83.

13. Presa, M.; Pérez-Ruiz, F.; Oyagüez, I.; Clin. Rheumatol. 2019, 38, 3521.

14. Caliceti, C.; Calabria, D.; Roda, A.; Anal. Bioanal. Chem. 2016, $408,8755$.

15. Elion, G. B.; Uric Acid 1978, 51, 485.

16. Khanna, S.; Burudkar, S.; Bajaj, K.; Shah, P.; Keche, A.; Ghosh, U.; Desai, A.; Srivastava, A.; Kulkarni-Almeida, A.; Deshmukh, N. J.; Dixit, A.; Brahma, M. K.; Bahirat, U.; Doshi, L.; Nemmani, K. V. S.; Tannu, P.; Damre, A.; B-Rao, C.; Sharma, R.; Sivaramakrishnan, H.; Bioorg. Med. Chem. Lett. 2012, 22 , 7543.

17. Wang, S.; Yan, J.; Wang, J.; Chen, J.; Zhang, T.; Zhao, Y.; Xue, M.; Eur. J. Med. Chem. 2010, 45, 2663.

18. Tang, H.; Zhao, D.; J. Iran. Chem. Soc. 2019, 16, 2659.

19. Di Petrillo, A.; González-Paramás, A. M.; Rosa, A.; Ruggiero, V.; Boylan, F.; Kumar, A.; Pintus, F.; Santos-Buelga, C.; Fais, A.; Era, B.; J. Enzyme Inhib. Med. Chem. 2019, 34, 519.

20. Fais, A.; Era, B.; Asthana, S.; Sogos, V.; Medda, R.; Santana, L.; Uriarte, E.; Matos, M. J.; Delogu, F.; Kumar, A.; Int. J. Biol. Macromol. 2018, 120, 1286.

21. Nam, K.; Lee, S.; Nat. Prod. Sci. 1999, 5, 165.

22. Burton, G. J.; Jauniaux, E.; Best Pract. Res., Clin. Obstet. Gynaecol. 2011, 25, 287.

23. Lin, Y. X.; Lin, H. T.; Chen, Y. H.; Wang, H.; Lin, M. S.; Ritenour, M. A.; Lin, Y. F.; Food Chem. 2020, 305, 125439.

24. Chang, W. S.; Lee, Y. J.; Lu, F. J.; Chiang, H. C.; Anticancer Res. 1993, 13, 2165.

25. Mo, S. F.; Zhou, F.; Lv, Y. Z.; Hu, Q. H.; Zhang, D. M.; Kong, L. D.; Biol. Pharm. Bull. 2007, 30, 1551.

26. Lin, S.; Zhang, G.; Pan, J.; Gong, D.; J. Photochem. Photobiol., B 2015, 153, 463.

27. Liu, L. L.; Ma, Y. J.; Chen, X. Q.; Xiong, X.; Shi, S. Y.; J. Chromatogr. B 2012, 887-888, 55.

28. Liu, L. L.; Yuan, M. M.; Huang, S. Q.; Li, J. J.; Li, D. F.; Zhao, L. N.; Appl. Sci. 2018, 8, 158.

29. Tang, X. S.; Tang, P.; Liu, L. L.; Molecules 2017, 22, 1036.

30. Wang, G. H.; Huang, X. Y.; Pei, D.; Duan, W. D.; Quan, K. J.; Li, X. T.; Di, D. L.; New J. Chem. 2016, 40, 3885. 
31. Xiao, J. B.; Zhao, Y.; Wang, H.; Yuan, Y.; Yang, F.; Zhang, C.; Yamamoto, K.; J. Agric. Food Chem. 2011, 59, 10747.

32. Yan, S.; Zhang, H.; Wang, J.; Zheng, F.; Dai, J.; Free Radical Biol. Med. 2015, 87, 300.

33. Xie, Y. X.; Liu, D. J.; Cai, C. L.; Chen, X. J.; Zhou, Y.; Wu, L. L.; Sun, Y. W.; Dai, H. L.; Kong, X. M.; Liu, P. F.; Int. J. Nanomed. 2016, 11, 3557.

34. Cao, X. N.; Shen, L. J.; Wu, S. D.; Yan, C.; Zhou, Y.; Xiong, G.; Wang, Y. C.; Liu, Y.; Liu, B.; Tang, X. L.; Guo, M.; Liu, D. Y.; Long, C. L.; Sun, M.; He, D. W.; Lin, T.; Wei, G. H.; Toxicol. Lett. 2017, 266, 1.

35. Yuan, X. H.; Fan, Y. Y.; Yang, C. R.; Gao, X. R.; Zhang, L. L.; Hu, Y.; Wang, Y. Q.; Jun, H.; J. Steroid Biochem. 2016, 155, 104.

36. Xu, J.; Xu, Q. S.; Chan, C. O.; Mok, D. K. W.; Yi, L. Z.; Chau, F. T.; Anal. Chim. Acta 2015, 870, 45.
37. Wang, F. R.; Zhang, Y.; Yang, X. B.; Liu, C. X.; Yang, X. W.; Xu, W.; Liu, J. X.; Molecules 2017, 22, 545.

38. Chen, R.; Wu, P.; Cai, Z.; Tang, L.; Ye, L.; Hou, C.; Yang, N.; Zhao, J.; J. Funct. Foods 2018, 47, 72.

39. Wang, Y. Q.; Tang, Y.; Liu, C. M.; Shi, C.; Zhang, Y. C.; Med. Chem. Res. 2016, 25, 1020.

40. Fu, L.; Sun, Y.; Ding, L.; Wang, Y.; Gao, Z.; Wu, Z.; Wang, S.; Li, W.; Bi, Y.; Food Chem. 2016, 203, 150.

41. Li, S.; Tang, L.; Bi, H.; Luminescence 2016, 31, 442.

42. Xiao, J.; Capanoglu, E.; Jassbi, A. R.; Miron, A.; Crit. Rev. Food Sci. Nutr. 2016, 56, S29.

43. Bernardo, I.; Bozinovski, S.; Vlahos, R.; Pharmacol. Ther. 2015, 155,60

44. Ray, G.; Husain, S. A.; Indian J. Exp. Biol. 2002, 40, 1213.

Submitted: December 3, 2019

Published online: June 5, 2020 